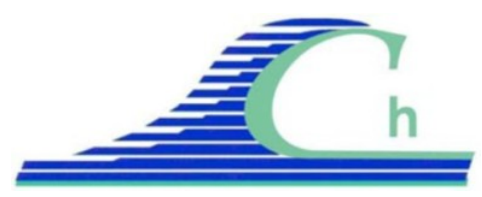

XII ${ }^{\text {èmes }}$ Journées Nationales Génie Côtier - Génie Civil

Cherbourg, 12-14 juin 2012

DOI:10.5150/jngcgc.2012.025-C C Editions Paralia CFL

disponible en ligne - http://www.paralia.fr - available online

\title{
A one-dimensional two-phase flow approach for sedimentation-consolidation modelling
}

\author{
Julien CHAUCHAT ${ }^{1}$, Sylvain GUILLOU ${ }^{2}$, \\ Damien PHAM VAN BANG ${ }^{3}$, Kim Dan NGUYEN $^{3}$
}

1. Laboratoire des Ecoulements Géophysiques et Industriels, UMR 5519, UJF, INPG, 1023 rue de de la piscine, 38400 Saint Martin d'Hères, France.

julien.chauchat@grenoble-inp.fr

2. Laboratoire Universitaire des Sciences Appliquées de Cherbourg, EA 4253, ESIX

Normandie - Université de Caen, BP 78, 50130 Octeville, France.

sylvain.guillou@unicaen.fr

3. Université Paris-Est, Saint-Venant Laboratory for Hydraulics, Joint Research Unit of CETMEF, EDF R \& D and ENPC- 8 quai Watier 78400 Chatou, France.

damien.pham-van-bang@developpement-durable.gouv.fr ;

dan.nguyen@saint-venant-lab.fr

\section{Résumé :}

Nous présentons un modèle diphasique pour la sédimentation-consolidation basé sur la résolution des équations de continuité et de quantité de mouvement pour les deux phases liquide et solide. La loi de Darcy-Gersevanov est utilisée pour la fermeture du transfert de quantité de mouvement entre les deux phases et le concept de "contrainte effective" est introduit pour tenir compte de la structuration du lit. Le modèle est validé par rapport à des données expérimentales hautement résolues pour les profils de concentration. Le bon accord obtenu entre les résultats numériques et les données expérimentales montre la capacité prédictive du modèle à deux phases.

\section{Mots-clés :}

Sedimentation - Consolidation - Two-phase flow - Numerical model

\section{Abstract:}

A two-phase flow model for sedimentation-consolidation process is presented. The model is based on solving the continuity and momentum equations for both fluid and solid phases. Darcy-Gersevanov's law is used for the closure of the momentum transfer between the two phases and the concept of "effective stress" is introduced to account for the bed structuring. These closure laws are validated against high resolution experimental data in terms of settling curves and concentration profiles. The good agreement obtained between numerical results and experimental data shows the predictive capability of the two-phase model.

\section{Keywords:}

Sedimentation - Consolidation - Two-phase flow - Numerical model 


\section{Introduction}

Sedimentation and consolidation are major physical processes of the sediment transport in Estuarine and Coastal Zones (ECZs). Sedimentation is the process of suspendedparticles settling whereas consolidation corresponds to the compaction of a soil skeleton under its own weight (i.e. TOORMAN, 1996). The latter is specific to cohesive sediment. The former is observed for both non-cohesive and cohesive sediment particles though it strongly differs due to the presence of particle-particle interactions and sediment heterogeneity in the cohesive case (flocculation). Two-phase models provide a general framework that allows the representation of the physical processes involved from the suspension to the consolidating bed such as interactions between fluid-solid particles, fluid-bottom as well as particle-particle interactions. No erosion/deposition fluxes needed to be empirically prescribed. TOORMAN (1996) has presented a unifying theory of sedimentation-consolidation derived from the two-phase equations that allows to recover Kynch's sedimentation theory at low sediment concentration (KYNCH, 1952) and Gibson's consolidation theory at higher sediment concentration (GIBSON et al., 1967). However no direct application to sedimentation-consolidation of two-phase model solving for both fluid and solid phases has been presented in the literature. Recently, first applications of two-phase model for fine-sediment transport in ECZs have been published (HSU et al., 2007; TORRES-FREYERMUTH \& HSU, 2010). These models did not account for consolidation processes. Only the hindered settling regime is considered and parameterized using an hindrance function. Improvements in modelling sedimentation and consolidation processes are needed for progressing twophase modelling of sediment transport in ECZs. In particular, closure laws for the twophase equations are required and need to be checked by comparison with experiments.

\section{Two-phase flow model}

The present two-phase model is based on averaged equations for each phase, fluid and sediment, inspired from the early work presented in CHAUCHAT \& GUILLOU (2008). The averaged equation for mass conservation and momentum conservation for each phase (1-5) reads:

$$
\begin{aligned}
& \alpha_{f}+\alpha_{s}=1 \\
& \frac{\partial\left(\alpha_{f} \rho_{f}\right)}{\partial t}+\frac{\partial\left(\alpha_{f} \rho_{f} w_{f}\right)}{\partial z}=0 \\
& \frac{\partial\left(\alpha_{s} \rho_{s}\right)}{\partial t}+\frac{\partial\left(\alpha_{s} \rho_{s} w_{s}\right)}{\partial z}=0 \\
& \frac{\partial\left(\alpha_{f} \rho_{f} w_{f}\right)}{\partial t}+\frac{\partial\left(\alpha_{f} \rho_{f} w_{f} w_{f}\right)}{\partial z}=-\alpha_{f} \frac{\partial p_{f}}{\partial z}+\alpha_{f} \frac{\partial \tau_{m}^{z z}}{\partial z}-\alpha_{f} \rho_{f} g+M_{f}^{z^{\prime}} \\
& \frac{\partial\left(\alpha_{s} \rho_{s} w_{s}\right)}{\partial t}+\frac{\partial\left(\alpha_{s} \rho_{s} w_{s} w_{s}\right)}{\partial z}=-\alpha_{s} \frac{\partial p_{s}}{\partial z}-\frac{\partial \sigma_{e}}{\partial z}+\alpha_{s} \frac{\partial \tau_{m}^{z z}}{\partial z}-\alpha_{s} \rho_{s} g+M_{s}^{z^{\prime}}
\end{aligned}
$$




\section{XII ${ }^{\text {èmes }}$ Journées Nationales Génie Côtier - Génie Civil \\ Cherbourg, 12-14 juin 2012}

where $\alpha_{f}, w_{f}, \rho_{f}$ are the volume fraction, vertical velocity and density of phase $k$; $M_{k}^{z^{\prime}}$ represents the fluid-particle interaction forces. $k$ stands either for $f$ for the fluid phase or for $s$ for the solid phase. $\tau_{m}^{z z}$ represents the viscous stress of the mixture; $p_{f}$ the fluid pressure, $\sigma_{e}$ the effective stress or particulate presssure and $g$ is the acceleration due to gravity. Equation (1) represents the global volume conservation that gives an additional equation.

The viscous stress of the mixture is given by:

$$
\tau_{m}^{z z}=2 \mu_{f}\left(1+\beta \alpha_{s}\right) \frac{\partial}{\partial z}\left(\alpha_{s} w_{s}+\alpha_{f} w_{f}\right)
$$

where $\beta$ is the amplification factor for viscosity. This parameter accounts for the nonNewtonian characteristics of the flow when the volume fraction of the solid phase reaches high values. The formulation proposed by GRAHAM (1981) is used:

$$
\begin{aligned}
& \beta=\frac{5}{2}+\frac{9}{4}\left(\frac{1}{1+d_{i p} / d}\right)\left[\frac{1}{2 d_{i p} / d}-\frac{1}{1+2 d_{i p} / d}-\frac{1}{\left(1+2 d_{i p} / d\right)^{2}}\right] \frac{1}{\alpha_{s}} \\
& \text { With } \frac{d_{i p}}{d}=\frac{1-\left(\alpha_{s} / \alpha_{s}^{\max }\right)^{1 / 3}}{\left(\alpha_{s} / \alpha_{s}^{\max }\right)^{1 / 3}}
\end{aligned}
$$

where $d_{i p}$ is the inter-particle spacing and $d$ is the particle diameter and $\alpha_{s}{ }^{\max }$ is the maximum solid volume fraction ( $\alpha_{s}^{\max }=0.625$ for maximum packing of spheres).

The heterogeneity of the suspension and the existence of electrochemical forces reponsible for particle aggregation did not allow to link the drag force to the one of a single particle. Therefore a more macroscopic point of view for the drag force must be adopted. Following TOORMAN (1996) the Darcy-Gersevanov's semi-empirical expression for the drag force is used in the two-phase model:

$$
M_{s}^{z^{n}}=-M_{f}^{z^{\prime \prime}}=\frac{\rho_{f} g}{K}\left(w_{f}-w_{s}\right)
$$

where $K(\mathrm{in} \mathrm{m} / \mathrm{s})$ represents the permeability.

The formulation proposed by CAMENEN \& PHAM VAN BANG (2011) is used that ensures a smooth transition of the settling velocity from the hindered settling regime to the permeability one by imposing the continuity of the settling velocity's first derivative against concentration at the gelling point (The reader is referred to the original paper for full details). Knowing that $W_{s}=K \alpha_{s}\left(\rho_{s} \rho_{f}-1\right)$ (TOORMAN, 1996) this formulation is rewritten in terms of the permeability. In the hindered regime the permeability is given by:

$$
\frac{K_{h}}{W_{s o}}=\frac{\rho_{f}}{\alpha_{s}\left(\rho_{s}-\rho_{f}\right)}\left(1-\alpha_{s}\right)^{n / 2}(1-\phi)^{n / 2-1}\left(1-\frac{\phi}{\phi_{\max }}\right)^{\phi_{\max }}
$$

where $W_{s o}$ is the asymptotic settling velocity at zero concentration, $n$ is the fractal dimension of flocs and $\phi=\alpha_{S}\left(\rho_{s}-\rho_{f}\right)\left(\rho_{f l o c}-\rho_{f}\right)$ is the volume fraction of flocs. It is assumed that the floc property (size and density) are fixed in space and time and are 
identical to the floc's property at the maximum concentration $\phi_{\max }$ (with $\phi_{\max }=0.85$ ), which corresponds to the gelling fraction $\alpha_{S}^{g e l}$. Therefore the flocs density is written as: $\rho_{\text {floc }} \rho_{f}+\left(\rho_{s}-\rho_{f}\right) \alpha_{s}^{g e l} / \phi_{\max }$.

$$
K=\left\{\begin{array}{ccc}
K_{h} & \text { if } & \alpha_{s} \leq \frac{\alpha_{s}^{g e l}}{\chi} \\
K_{h}^{g e l}\left(\frac{\chi \alpha_{s}}{\alpha_{s}^{g e l}}\right)^{-\frac{2}{3-n}+1} & \text { if } & \alpha_{s}>\frac{\alpha_{s}^{g e l}}{\chi}
\end{array}\right.
$$

where $K_{h}{ }^{g e l}$ corresponds to the value of $K_{h}$ at $\alpha_{s}=\chi$. The values of the following parameters $W_{S O}, n, \alpha_{S}{ }^{g e l}$ and $\chi$ need to be determined from the experiments.

The effective stress represents both permanent contacts between particles in concentrated suspension and inter-particle collisions during sedimentation. The following closure is proposed:

$$
\sigma^{\prime}=\left\{\begin{array}{ccc}
0 & \text { if } & \alpha_{s}<\alpha_{s}{ }^{g e l} \\
\sigma_{0}\left[\left(1-\frac{\alpha_{s}-\alpha_{s}^{g e l}}{\alpha_{s, \max }}\right)^{-\frac{2}{3-n}}-1\right] & \text { if } & \alpha_{s} \geq \alpha_{s}^{g e l}
\end{array}\right.
$$

with this formulation, the effective stress vanishes at $\alpha_{S}^{g e l}$ and only $\sigma_{0}$ need to be determined.

The set of equations (1)-(5) are solved by a fractional technique based on a projection method. A finite difference technique is used for the discretisation of momentum conservation equations on a staggered grid. The governing equations are solved implicitly.

\section{Results}

Experimental data for sedimentation-consolidation of Le Havre's mud (PHAM VAN BANG, 2007) are used herein. Experiments were performed at Navier Laboratory (Ecole des Ponts ParisTech, Champs-sur-Marne, France) on a Bruker 24/80 DBX MRI (Magnetic Resonant Imaging) facility. The mud was treated using potassium permanganate and sieved to obtain fine particles, the diameter of which is smaller than $125 \mu \mathrm{m}$. The granulometry of the mud has been obtained using a laser granulometer and the median diameter is evaluated at $d_{50}=7.5 \mu \mathrm{m}$. The density of dry sediment is estimated at $2590 \mathrm{~kg} \mathrm{~m}^{-3}$ by a helium pycnometer. Three initial homogeneous solid volume fractions $1.2 \%, 2.2 \%$ and $5.2 \%$ were tested and the time evolution of the solid volume fraction profiles were measured using the Proton MRI facility at LMSGC (see PHAM VAN BANG, 2007, for details).

Fig. 1a presents the experimental and numerical settling curves and Fig. 1b presents the experimental and numerical solid volume fraction profiles at different times for the three initial solid volume fractions $\alpha_{S}^{0}=1.2 \%, \alpha_{S}{ }^{0}=2.2 \%$, and $\alpha_{S}{ }^{0}=5.2 \%$. At first the experimental measurements are used to determine the closure's parameters $W_{S O}, n, \alpha_{S}^{g e l}$, 


\section{XII ${ }^{\text {èmes }}$ Journées Nationales Génie Côtier - Génie Civil \\ Cherbourg, 12-14 juin 2012}

$\chi$ and $\sigma_{0}$ as explained below. The values of the parameters are: $\alpha_{s}{ }^{g e l}=0.025$, $\rho_{\text {floc }}=1047 \mathrm{~kg} \mathrm{~m}^{-3}, W_{S O}=210^{-4} \mathrm{~m} / \mathrm{s}, n=2.55$ and $\chi=1.283$ for the permeability closure following the method presented by TOORMAN (1999) and CAMENEN \& PHAM VAN BANG (2011). For the effective stress closure the final concentration profile for experiment at initial solid volume fraction $\alpha_{s}^{0}=5.2 \%$ are used to determine $\sigma_{0}=0.14 \mathrm{~Pa}$ and $\alpha_{S}{ }^{\max }=0.14$.

For the initial solid volume fraction at $1.2 \%$, the experimental settling curve presents a slope break around 400 seconds, which represents the transition between the hindered settling regime and the permeability one (existence of a gelling point). This slope break is less evident for the $2.2 \%$ initial solid volume fraction and inexistent for the last case $\left(\alpha_{S}^{0}=5.2 \%\right)$, which is in consolidation since the beginning of the experiment.

A uniform 300-nodes mesh $\left(\Delta z=3.310^{-4} \mathrm{~m}\right)$ and a time step of $\Delta t=10^{-2} \mathrm{~s}$ are used for the simulations. The sensitivity to the time step has been checked and the numerical results are converged against $\Delta z$.

The profile of volume fraction (Fig. 1b) continuously increases with the vertical downward even inside the cohesive bed, which is characteristic for a solid skeleton compaction, (i.e. existence of effective stresses). The best results are obtained for the first two experiments $\left(\alpha_{S}^{0}=1.2 \%\right.$ and $\left.\alpha_{S}^{0}=2.2 \%\right)$. The difference observed for the last case $\left(\alpha_{s}^{0}=5.2 \%\right)$ can be attributed to a modification of the internal structure. This experiment is clearly in consolidation since the beginning, contrary to the two first ones. Therefore, the dependency of the permeability to the sediment concentration is certainly different from the $1.2 \%$ case, for which the permeability has been calibrated.

Finally, those results show that the essential physical ingredients are taken into account in the proposed closure laws. The settling curves and the solid volume fraction profiles are in rather good agreement with the experiments for medium to high concentrations of cohesive material. The present results demonstrate the ability of the proposed two-phase model to reproduce almost quantitatively sedimentation-consolidation of estuarine mud. The main advantages of the two-phase model compared with classical ones come from(i) the computational domain extends from the water free surface to the consolidated sediment bed and (ii) the calculation of the fluid pressure in the suspension and inside the consolidating sediment bed (permeability regime).

However, the proposed closure laws are based on the limited assumptions. In particular, considering constant aggregate properties ( $\rho_{\text {floc }}=$ constant and $n=$ constant $)$ is obviously too restrictive. As reported by CHAKRABORTI et al. (2003), the fractal dimension varies during the aggregation process. WINTERWERP and VAN KESTEREN (2004) found that the fractal dimension is larger than 2.6 for cohesive sediment beds, whilst for suspended floc is usually lower than 2.2. Considering constant floc properties therefore neglects this effect and certainly constitutes the main limiting assumption of the present model. 

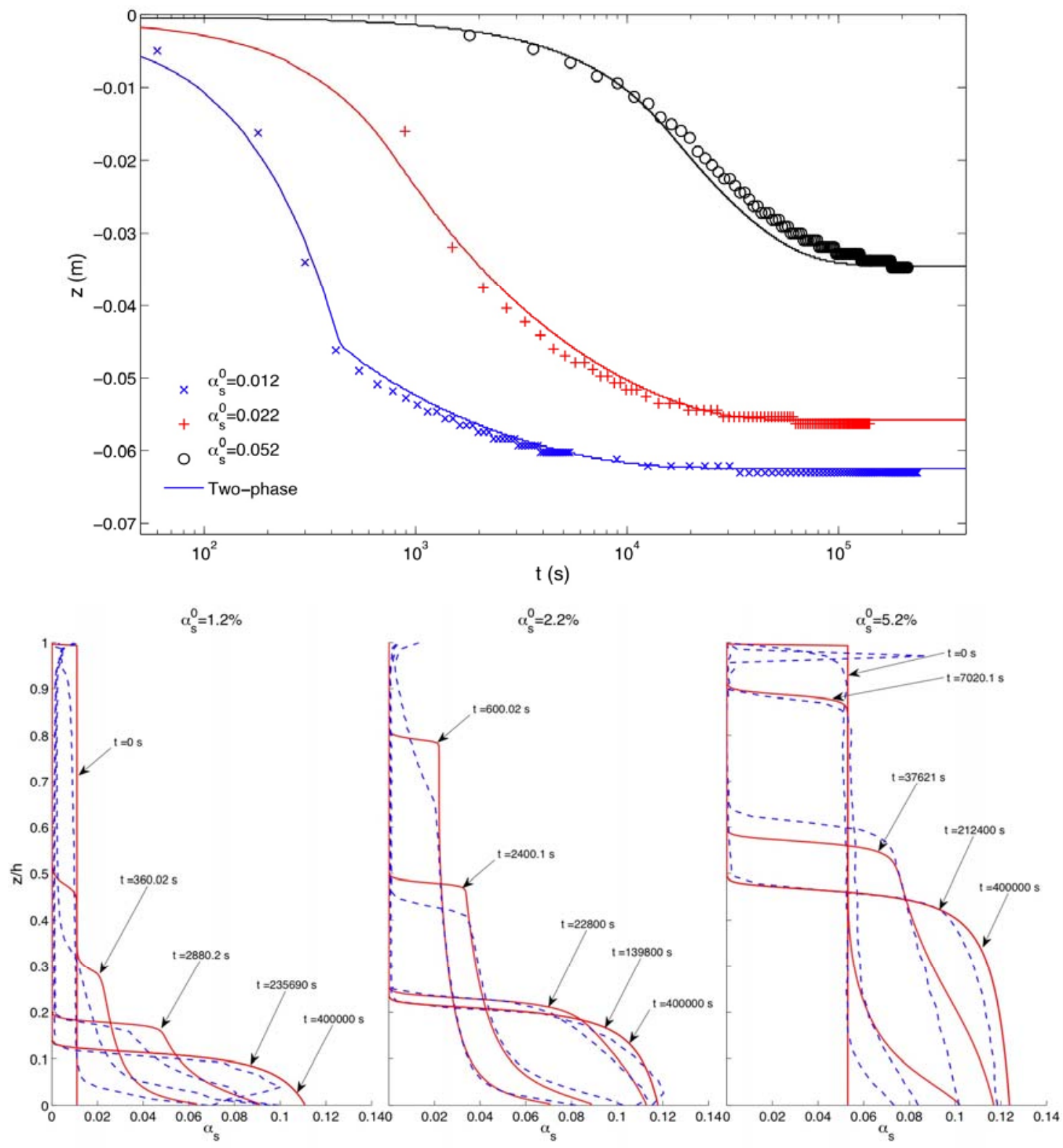

Figure 1: Comparison of two-phase model results with experiments for initial concentrations $\alpha_{S}{ }^{0}=1.2 \%, \alpha_{S}{ }^{0}=2.2 \%$, and $\alpha_{S}{ }^{0}=5.2 \%$. a) Settling curves: time evolution of the mud-clear water interface position (symbols: experiments; lines: model) and b) solid volume fraction profiles (dashed blue lines: experiments; solid red lines: model).

\section{Conclusion}

In this paper a vertical one-dimensional two-phase flow model has been presented that has been extensively validated against high resolution experimental data (concentration profiles) for sedimentation-consolidation of mud. The closure laws are Darcy drag for the fluid-particles interaction and the effective stress. This stress represents the 
resistance of the solid skeleton to compression. The results presented in this paper demonstrate the ability of the proposed model to quantitatively reproduce the interface dynamics and the associated concentration profiles. The explicit calculation of the fluid pressure from the suspension to the consolidated bed represents a major advantage of the two-phase approach compared with the classical Kynch or Gibson approaches.

There remain some limitations in the model mainly because of the assumption of constant aggregate density $\left(\rho_{f l o c}\right)$ and fractal dimension $(n)$. Indeed, during the sedimentation -consolidation, floculation and defloculation processes occur and would change both the permeability and the effective stress. This phenomenon is not easily measurable in experiments and there are research perspectives on this issue.

Finally, the implementation of the proposed closure laws in a 2D or 3D two-phase flow model will certainly allow for a more realistic modelling of mud-flow interactions in Estuarine and Coastal Zones.

\section{Acknowledgments}

The authors thank the CETMEF (Centre d'Etude Technique Maritime Et Fluvial / French centre for marine and fluvial technical studies) for its financial support (contract $\left.\mathrm{N}^{\circ} 05-510006-000-228-6034\right)$.

\section{References}

CAMENEN B., PHAM VAN BANG D. (2011). Modelling the settling of suspended sediments for concentrations close to the gelling concentration. Continental Shelf Research, vol. 31, pp S106-S116. doi:10.1016/j.cs.2010.07.003

CHAKRABORTI R., GARDNER K., ATKINSON J., VAN BENSCHOTEN J. (2003). Changes in fractal dimension during aggregation. Water Research 37, pp 873-883. doi:10.1016/S0043-1354(02)00379-2

CHAUCHAT J., GUILLOU S. (2008). On turbulence closures for two-phase sedimentladen flows models. Journal Geophysical Research-Oceans 113, 20.

GIBSON R.E., ENGLUND G.L., HUSSEY M.J.L. (1967). The theory of onedimensional consolidation of saturated clays. Géotechnique 17, 2, pp 61-273.

GRAHAM A.L. (1981). On the viscosity of suspensions of solide spheres. Applied Science Research 37, pp 275-286. doi:10.1007/BF00951252

HSU T.J., TRAYKOVSKI P.A., KINEKE G.C. (2007). On modeling boundary layer and gravity-driven fluid mud transport. J. Geophys. Res. 112 (C4). doi:10.1029/2006JC003719 KYNCH G. (1952). A theory of sedimentation. Transactions Faraday Society 48, pp 166-176. doi:10.1039/tf9524800166

PHAM VAN BANG D. (2007). Rhéophysique des vases : rhéologie et sédimentation. Tech. rep., LCPC-CETMEF.

TOORMAN E.A. (1996). Sedimentation and self-weight consolidation: general unifying theory. Géotechnique 46, pp 103-113. doi:10.1680/geot.1996.46.1.103 
Thème 2 - Dynamique sédimentaire

TOORMAN E.A. (1999). Sedimentation and self-weight consolidation: constitutive equations and numerical modelling. Géotechnique 49, pp 709-726. doi:10.1680/geot.1999.49.6.709

TORRES-FREYERMUTH A., HSU T.-J. (2010). On the dynamics of wave-mud interaction: A numerical study. J. Geophys. Res. 115 (C7). doi:10.1029/2009JC005552

WINTERWERP J., VAN KESTEREN W. (2004). Introduction to the Physics of Cohesive Sediment Dynamics in the Marine Environment. Elsevier. 